This document is the accepted manuscript version of the following article:

C. Wäckerlin, T. Kartick, J. Girovsky, J. Nowakowski, T. Hählen, A. Shchyrba, D. Siewert, A. Kleibert, F. Nolting, P. M. Oppeneer, T. A. Jung, N. Ballav

Ammonia Coordination Introducing a Magnetic Moment in On-Surface Low-Spin Porphyrin

Angewandte Chemie International Edition, 2013, 52, 4568-4571, https://dx.doi.org/10.1002/anie.201208028

\title{
Ammonia Coordination Introducing a Magnetic Moment in On-Surface Low-Spin Porphyrin**
}

\author{
Christian Wäckerlin, Kartick Tarafder, ${ }^{+}$Jan Girovsky, Jan Nowakowski, Tatjana Hählen, Aneliia \\ Shchyrba, Dorota Siewert, Armin Kleibert, Frithjof Nolting, Peter M. Oppeneer, Thomas A. Jung* \\ and Nirmalya Ballav*
}

The controlled manipulation of spin-states in atoms/molecules is of profound interest towards the design of future spin-based devices. ${ }^{[1,2]}$ A prominent example of how spin states are modified ( $\mathrm{S}=2 \leftrightarrow \mathrm{S}=0$ ) can be found in nature's $\mathrm{Fe}$ (II) porphyrin moiety within hemoglobin and its coordination with the $\mathrm{O}_{2}$ ligand. ${ }^{[3]}$ Recently, we have implemented this concept in a synthetic onsurface arrangement using metallo-porphyrins adsorbed on ferromagnetic surfaces. By axial coordination with an external NO ligand the induced magnetic moment in the $(S=1 / 2) \mathrm{Co}(\mathrm{II})$ porphyrin has been switched-off. ${ }^{[4]}$ These experiments depend on a characteristic property of paramagnetic metallo-porphyrins as well as phthalocyanines: their interfacial chemical interaction with the ferromagnetic surface-ligand induces a magnetic moment stable up to room temperature. ${ }^{[4,5]}$ Axial coordination can also be used to control the magnetic anisotropy ${ }^{[6]}$ as well as the strength and sign of the exchange interaction ${ }^{[4 \mathrm{~b}]}$.

Controlling on-surface/interface $\quad$ spin-systems ${ }^{[4,5 \mathrm{j}, \mathrm{k}, 6,7]}$ is a

[*] C. Wäckerlin, J. Girovsky, J. Nowakowski, T. Hählen, Dr. D. Siewert, Prof. T. A. Jung

Laboratory for Micro and Nanotechnology, Paul Scherrer Institute, 5232 Villigen-PSI (Switzerland), E-mail: thomas.jung@psi.ch

\section{Prof. N. Ballav}

Department of Chemistry, Indian Institute of Science Education and Research, Pune 411008 (India), E-mail: nballav@iiserpune.ac.in

Dr. K. Tarafder, ${ }^{\ddagger}$ Prof. P. M. Oppeneer

Department of Physics and Astronomy, University of Uppsala, Box 516, S-751 20 Uppsala (Sweden)

‡Present address: Materials Science Division, Lawrence,

Berkeley National Laboratory, CA 94720 (USA)

\section{A. Shchyrba}

Department of Physics, University of Basel, 4056 Basel (Switzerland)

Dr. A. Kleibert, Prof. F. Nolting

Swiss Light Source, Paul Scherrer Institute, 5232 VilligenPSI (Switzerland)

[**] We gratefully acknowledge financial supports from the National Centre of Competence in Research Nanosciences (NCCR-Nano), Swiss Nanoscience Institute (SNI), Swiss National Science Foundation, Holcim Foundation for the Advancement of Scientific Research, Switzerland; and from the Swedish-Indian Research Links Programme and Swedish National Infrastructure for Computing (SNIC), Sweden. Part of this work has been performed at the SIM beamline of SLS. The authors sincerely thank Rolf Schelldorfer for technical support all throughout. N.B. thanks K. N. Ganesh (IISER Pune) for the support during beamtimes as SLS.

Supporting information for this article is available on the WWW under http://www.angewandte.org or from the author prerequisite for applications in organic spintronics ${ }^{[1]}$ which makes this research field increasingly popular. Recently, we combined chemically directed self-assembly and coordination-chemistry to obtain selectively switchable, highly-ordered supramolecular 2D spin-arrays ${ }^{[5 j]}$. Concerning chemical control of the magnetic moment only off-switching ${ }^{[4,5 \mathrm{j}]}$ and spin-tuning ${ }^{[4 \mathrm{~b}, 5 \mathrm{k}]}$, i.e. switching spin-on $\rightarrow$ spin-off and spin-on $\rightarrow$ spin-on' (a modified spin-state) have been established. So far this set of on-surface chemical spin-operations was incomplete since the spin-off $\rightarrow$ spin-on case was missing. Generally, switching the spin in metal-organic complexes by external ligands to the on-state is more difficult to achieve than switching to the off-state, since chemical bonding has to overcome spin-pairing energy. An additional complication arises from the possibility that the surface can modify the spin-states before as well as after the axial ligation. ${ }^{[4 b]}$ This can also lead to spin-quenching on the surface ${ }^{[4 \mathrm{~b}, 8]}$ Here we report on the first demonstration of an onsurface chemical spin on-switch, for $\mathrm{Ni}(\mathrm{II})$ porphyrins $(\mathrm{S}=0)$ adsorbed on a ferromagnetic (FM) Co substrate, by the diamagnetic $(\mathrm{S}=0)$ external $\mathrm{NH}_{3}$ ligand. A schematic representation of this spin on-switch $(\mathrm{S}=0 \leftrightarrow \mathrm{S}=1)$ is shown in Fig. 1a.

To study this effect, Ni(II) tetraphenylporphyrin (NiTPP; cf. Fig. 1a) molecules were thermally sublimed in ultra-high vacuum onto clean $\mathrm{Co}$ thin films on $\mathrm{Cu}(001)$ single crystals. $^{[4,5 \mathrm{e}, \mathrm{f}, \mathrm{j}]}$ For a description of the methods see the Supporting Information.
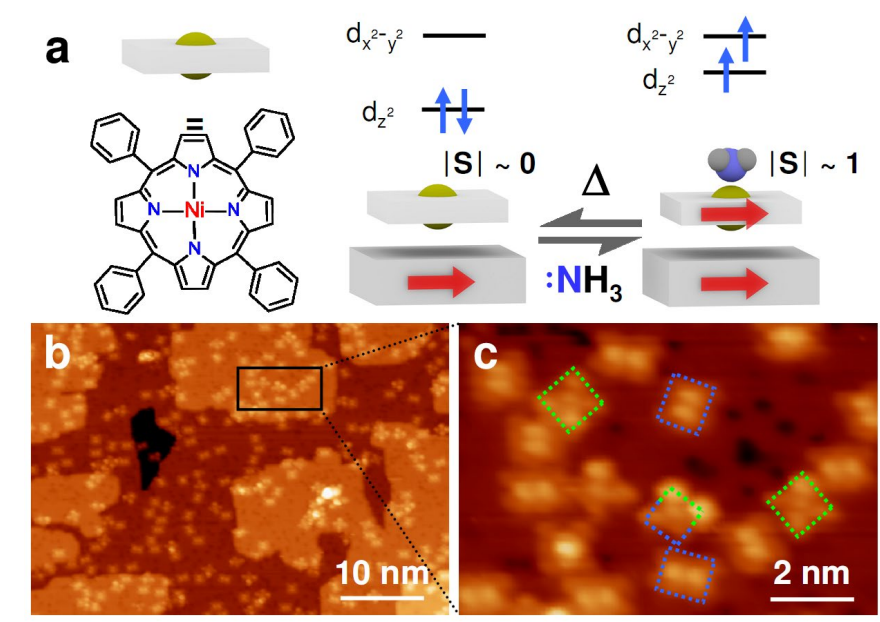

Figure 1. (a) Schematic representation of NiTPP and of the reversible spin on-switch $(\mathrm{S}=0 \leftrightarrow \mathrm{S}=1)$. The molecular orbital diagram shows that the $\mathrm{NH}_{3}$-ligand increases the energy of the $3 \mathrm{~d}_{z}^{2}$ orbital and thus allows a $\mathrm{S}=1$ high-spin state (vide infra). (b) Constant current STM image of NiTPP on $\mathrm{Co}(001)$ (tunneling parameters: $20 \mathrm{pA}, 650 \mathrm{mV}$, $\mathrm{W}$-tip) without $\mathrm{NH}_{3}$. The considerable molecule-surface interaction leads to irregular arrangement of the ad-molecules. (c) The zoom-in STM image shows that the NiTPP molecules are found in either one 
of two conformations: saddle-shape (blue rectangles) and flat (green squares).

In scanning tunneling microscopy (STM) experiments (Fig. 1b), we consistently find the molecules adsorbed in a random fashion on Co and Ni substrates, ${ }^{[4,5 \mathrm{f}]}$ in contrast to self-assembly of NiTPP on Au and $\mathrm{Ag}$ substrates. ${ }^{[9 \mathrm{a}]}$ Most of the NiTPP molecules on the Co surface can be recognized as rectangular shapes - the so-called saddle-shape conformation ${ }^{[9 b]}$ (Fig. 1c), while a minority of the molecules is observed as four-leaf clovers, ${ }^{[5 \mathrm{f}]}$ i.e. in the flat, squareplanar conformation of the free molecule. The adsorption-induced saddle-shape conformation is characterized by a tetrahedrally distorted macrocycle ${ }^{[9 b, c]}$ and its coexistence with the flat conformation has been observed in our previous studies. ${ }^{[4]}$ Note, that an intermediate conformation (half flat, half saddle-shape) is also observed (Fig. 1c, marked half green, half blue). STM data obtained after $\mathrm{NH}_{3}$-exposure at $78 \mathrm{~K}$ depicts bright blurry protrusions which partly have a streak-like appearance ${ }^{[5 j, 10]}$ (see Supporting Information). This suggests considerable degrees of freedom of the $\mathrm{NH}_{3}$-ligand or partial removal of $\mathrm{NH}_{3}$ during the scanning process. $^{[5 \mathrm{j}, 10]}$

The electronic and magnetic properties of both ad-molecules (NiTPP) and substrate (Co(001) thin films), as well as the magnetochemical effect induced by the $\mathrm{NH}_{3}$-ligand were investigated by element-specific X-ray absorption spectroscopy (XAS) and X-ray magnetic circular dichroism (XMCD) ${ }^{[11 a]}$ measurements (Fig. 2) at the at the Surface/Interface: Microscopy (SIM) beamline of the Swiss Light Source (SLS) ${ }^{[11 b]}$. For 3d transition metals, the absorption cross-section at the $\mathrm{L}_{3 ; 2}$ edges $(2 p \rightarrow 3 d$ electronic transitions) provides element-specific information on the magnetization of the surface adsorbed transition- metal complexes (here NiTPP) and the substrate (here Co) separately.

Fig. 2 shows the $\mathrm{Ni}$ and $\mathrm{Co} \mathrm{L}_{2 ; 3}$ edge XAS/XMCD signals sequentially obtained at $\sim 70 \mathrm{~K}$ with the substrate kept in its remanent magnetization on the native NiTPP/Co system (a), after exposure to $\mathrm{NH}_{3}$ gas (b), after thermal desorption of $\mathrm{NH}_{3}$ (c) and, finally, after re-exposure to $\mathrm{NH}_{3}$ gas (d). Note that the $\mathrm{Ni} \mathrm{L}_{3 ; 2}$ edge $\mathrm{XAS}$ is affected by far-edge oscillations, originating from the Co thin film substrate, giving rise to a slowly varying background in XAS/XMCD signals. In the main panels we show the spectra upon subtraction of the background measured on a reference substrate.

For native NiTPP/Co, the absence of an XMCD signal demonstrates that the adsorption of the molecules on the Co substrate alone does not induce a magnetic dipole moment in the $\mathrm{Ni}^{2+}$ central ion (Fig. 2a). The exposure with $\mathrm{NH}_{3}$, however, results in a clear XMCD signal evidencing the presence of a magnetic moment on the $\mathrm{Ni}^{2+}$ center (Fig. 2b). Annealing to $\sim 300 \mathrm{~K}$ restores the initial spin-off state and subsequent $\mathrm{NH}_{3}$ exposure leads to the recovery of the spin-on state (Fig. $2 \mathrm{c}$ and $2 \mathrm{~d}$ ). The spin-on state is characterized by a FM coupling to the substrate as indicated by the parallel red arrows in Fig. 2. Such coupling for paramagnetic porphyrins and phthalocyanines in contact with ferromagnetic substrates has been observed earlier ${ }^{[5 a]}$ and studied in detail. ${ }^{[4,5]}$ However, in the presented here case the FM coupled spin, confirmed by the observed change in the sign of the Co and Ni XMCD signals after remagnetizing the substrate in the opposite direction, is observed only in presence of the axial $\mathrm{NH}_{3}$ ligand. The magnetic signature of the substrate remains unaffected (cf. Co-XMCD signals in Fig. 2e-h) in the sequential processes of $\mathrm{NH}_{3}$ coordination/decoordination, i.e. the switching between the molecular spin-off and spin-on states occurs in the presence of the substrate magnetization and its exchange interaction with the central metal ion of the molecule.

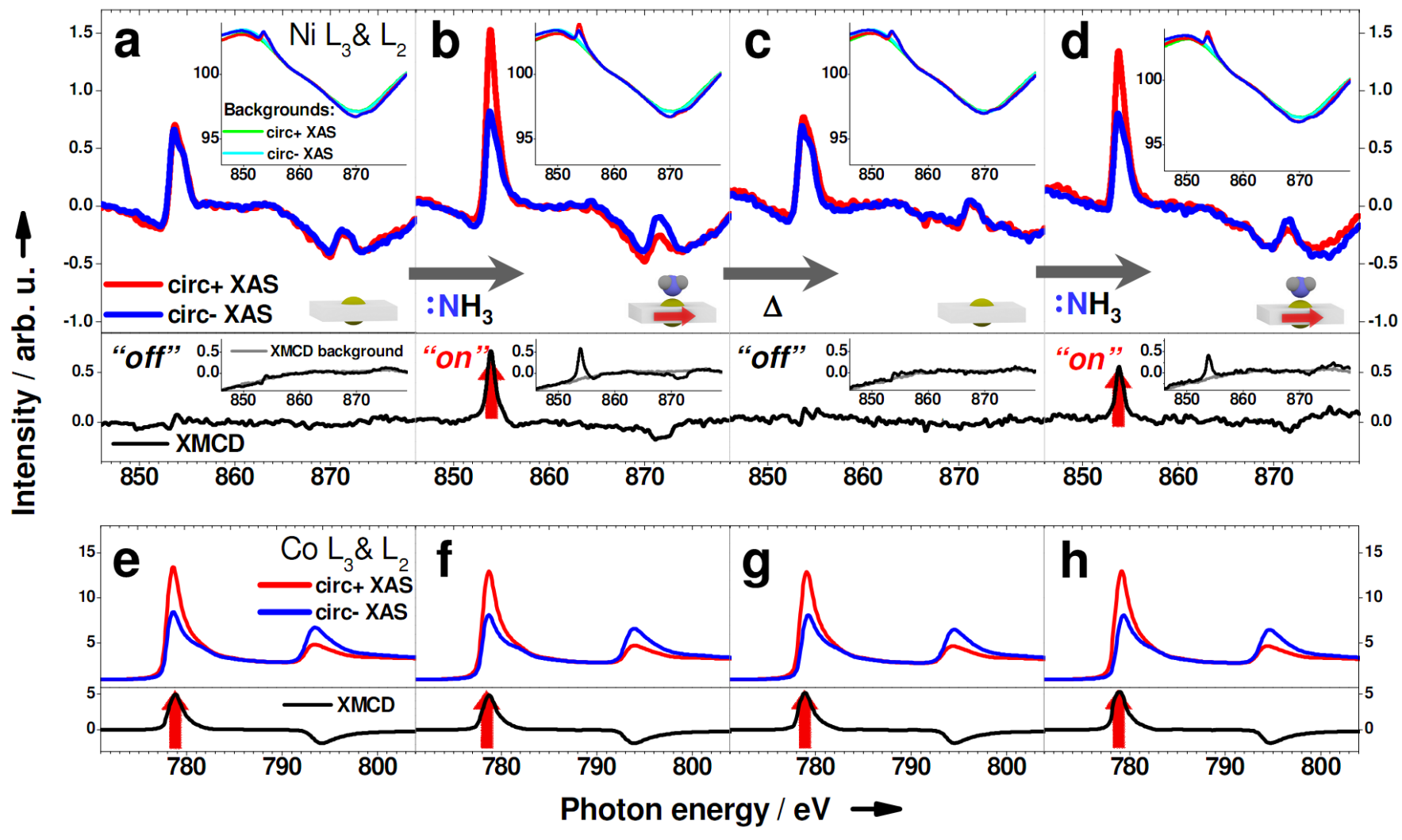


Figure 2. XAS/XMCD of $\mathrm{Ni}$ in the molecule and the Co substrate of the native NiTPP/Co (a,e), after exposure to $\mathrm{NH}_{3}$ gas (b,f), after thermal desorption $(\Delta)$ of $\mathrm{NH}_{3}(\mathrm{c}, \mathrm{g})$ and after re-exposure to $\mathrm{NH}_{3}$ gas $(\mathrm{d}, \mathrm{h})$. The spectra were recorded at $\sim 70 \mathrm{~K}$. At the Ni $\mathrm{L}_{3 ; 2}$ edge $\mathrm{XAS} / \mathrm{XMCD}$ data, the respective backgrounds as shown in the insets (green/cyan for circ+/circ- XAS and gray for XMCD), have been subtracted. The original spectra (red/blue for circ+/circ- XAS and black for XMCD) are also shown in the insets. In absence of $\mathrm{NH}_{3}(\mathrm{a}, \mathrm{c})$, no XMCD signal is observed in Ni (spinoff state). The red arrows indicate the presence of magnetic dipole moments.

The origin of the induced magnetic moment is related to the increase of the $\mathrm{Ni}$ ion's coordination number upon exposure to $\mathrm{NH}_{3}$. Four-coordinated $\mathrm{Ni}^{2+}$ complexes are usually in the low-spin $(\mathrm{S}=0)$ state. ${ }^{[12]} \mathrm{Ni}^{2+}$ ions with a coordination number of five (square pyramidal) or six (octahedral) are usually paramagnetic high-spin $(\mathrm{S}=1)$ species. ${ }^{[13]}$ However, the nature of the ligand, i.e. whether it acts as a $\sigma$-donor or as a $\pi$-acceptor, plays a crucial role for the thermodynamic stability of the coordination bond. ${ }^{[13 c]}$ Notably, we can observe this low-spin to high-spin transition also by XPS as an increase in the full width at half maximum of the $\mathrm{Ni} 2 \mathrm{p}_{3 / 2}$ spectral feature (see Supporting Information).

To explain our experimental observations and to provide detailed insight into the on-surface molecular spin-switching, numerical simulations based on density functional theory were performed taking additional Hubbard interactions $(\mathrm{DFT}+\mathrm{U})$ into account (Fig. 3). The calculations were performed on Ni-porphine, i.e. without phenyl substitution, to manage the computational efforts $^{[4,5 b-e, 14]}$. Note that in view of the coexistence of different conformations, local experiments, e.g., spin-polarized STM, would be desirable to correlate conformation and magnetochemistry. For Ni-porphine on $\mathrm{Co}(\mathrm{NiP} / \mathrm{Co})$, we find that the $3 \mathrm{~d}$ orbital local magnetic density of states (LMDOS) of Ni is equally distributed over the two spin-channels, i.e. spin $\uparrow$ and spin $\downarrow$; hence the magnetic dipole moment of $\mathrm{NiP}$ on $\mathrm{Co}$ is not present $(\mathrm{S}=0)$. The calculated electronic configuration, approximately $\left(\mathrm{d}_{\mathrm{xy}}\right)^{2}\left(\mathrm{~d}_{\mathrm{yz}}, \mathrm{d}_{\mathrm{xz}}\right)^{4}$ $\left(\mathrm{d}_{\mathrm{z}}{ }^{2}\right)^{2}\left(\mathrm{~d}_{\mathrm{x}-\mathrm{y}}^{2}\right)^{2}$, corresponds well to the free Ni(II) porphyrin.

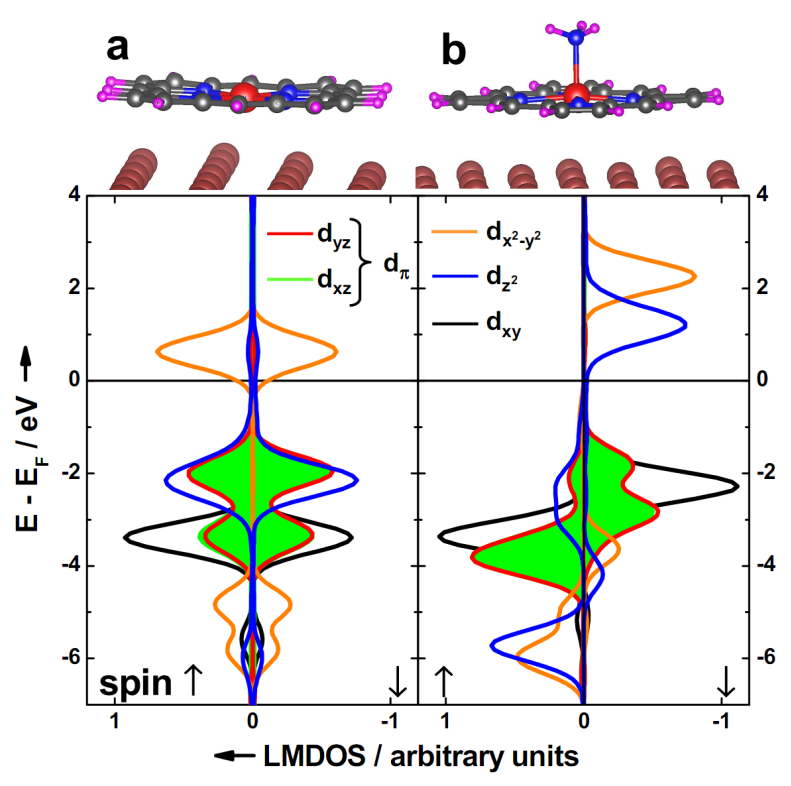

Figure 3. DFT+U calculations presenting the spin-projected 3d orbital local magnetic density of states (LMDOS) for the Ni-porphine/Co system with $\mathrm{S}=0$ before $(\mathrm{a})$ and with $\mathrm{S}=1$ after $(\mathrm{b})$ reaction with $\mathrm{NH}_{3}$. The given energies are with respect to the Fermi-level $\left(E_{F}\right)$. The calculations show that the $\mathrm{NH}_{3}$ ligation leads to an increased energy of the $\mathrm{d}_{z}^{2}$ orbital (due to overlap with the lone-pair of the $\mathrm{NH}_{3}$-ligand), shifting it closer in energy to the $d_{x}^{2}-y$ orbital and allowing for a highspin $(S=1)$ state being FM coupled to the Co substrate.
Through $\mathrm{NH}_{3}$ coordination, the $3 \mathrm{~d}$ LMDOS of $\mathrm{Ni}^{2+}$ changes into $\left(\mathrm{d}_{\mathrm{xy}}\right)^{2}\left(\mathrm{~d}_{\mathrm{yz}}, \mathrm{d}_{\mathrm{xz}}\right)^{4}\left(\mathrm{~d}_{\mathrm{z}}^{2}\right)^{1}\left(\mathrm{~d}_{\mathrm{x}-\mathrm{y}}^{2}\right)^{1}$, revealing singly occupied and $\mathrm{FM}$ coupled $\mathrm{d}_{\mathrm{z}}^{2}$ and $\mathrm{d}_{\mathrm{x}-\mathrm{y}}^{2}$ orbitals. The magnetic moment is $\sim 1.61 \mu_{\mathrm{B}}$ on the $\mathrm{Ni}$ ion and $\sim 0.06 \mu_{\mathrm{B}}$ on each of the nitrogens of the porphyrin. Moreover, the Ni ion is pulled-up from the porphyrin plane towards the $\mathrm{NH}_{3}$ ligand. Note that, depending on the electronic configuration $\mathrm{NH}_{3}$ can also act as a spin-off switch. ${ }^{[5 \mathrm{j}, 7]}$ The calculated Ni-Co distance for $\mathrm{NH}_{3}-\mathrm{NiP} / \mathrm{Co}(3.59 \AA)$ is significantly longer than the value obtained for the native $\mathrm{NiP} / \mathrm{Co}(3.09 \AA)$ system, consistent with the observation of a surface spin-trans effect ${ }^{[4]}$ Notably, the coordination of the Co surface-ligand ${ }^{[4,15]}$ to the $\mathrm{Ni}^{2+}$ ion is identified by a broadening of the calculated $3 \mathrm{~d}_{\mathrm{z}}^{2}$ LMDOS, however, this occurs without modification of the total molecular magnetic moment. Furthermore, the calculations show an increase of the $\mathrm{Ni}-$ $\mathrm{N}_{\text {porphine }}$ distance from $1.98 \AA$ to $2.05 \AA$. This increase has been attributed for a similar system to the reduced formal bond-order due to the presence of an un-paired electron in the anti-bonding $\mathrm{d}_{\mathrm{x}-\mathrm{y}}^{2}$ orbital of $\mathrm{NH}_{3}$-NiTPP. ${ }^{[13 \mathrm{~b}]}$ Note, that the $\mathrm{NH}_{3}$-induced FM coupled spin-density is distributed across the Ni-porphyrin's nitrogens and the $\mathrm{NH}_{3}$ ligand $\left(0.06 \mu_{\mathrm{B}}\right)$. The spin density sums up to $\sim 1.92 \mu_{\mathrm{B}}$, corresponding to a molecular spin state of $\mathrm{S}=1$, consistent with the two singly-occupied levels seen in Fig. 3 b.

In conclusion, we have provided evidence for the capability of $\mathrm{NH}_{3}$ to act as an on-switch for the spin of the NiTPP/Co system and confirmed the surface spin-trans effect. ${ }^{[4]}$ Notably, the observation of a magnetic moment in the molecule only after $\mathrm{NH}_{3}$ exposure rules out that the ligand quenches the magnetic moment of the substrate. The presented findings are of fundamental interest and provide a showcase for magnetochemistry in an on-surface setting. The consequence of ligation-induced transitions on spin multiplicity and magnetic moment are uniquely probed by XPS and XMCD, respectively. Moreover, they open-up new possibilities to control magnetic moments down to the single-molecule level by chemical stimuli. Possible applications include the use of this system in a magnetochemical sensor and in molecular spintronics.

Received: ((will be filled in by the editorial staff))

Published online on ((will be filled in by the editorial staff))

Keywords: Surface chemistry, Magnetic properties, Porphyrinoids, Xray absorption spectroscopy, Density functional calculations

[1] a) O. Kahn, K. J. Martinez, Science 1998, 279, 44-48; b) V. A. Dediu, L. E. Hueso, I. Bergenti, C. Taliani, Nat. Mater. 2009, 8, 707-716.

[2] a) A. A. Khajetoorians, J. Wiebe, B. Chilian, R. Wiesendanger, Science 2011, 332, 1062 -1064; b) S. Sanvito, Chemical Society Reviews 2011, 40, 3336 .

[3] J. M. Berg, J. L. Tymoczko, L. Stryer, Biochemistry, W.H. Freeman, New York, 2002.

[4] a) C. Wäckerlin, D. Chylarecka, A. Kleibert, K. Müller, C. Iacovita, F. Nolting, T. A. Jung, N. Ballav, Nat. Commun. 2010, 1, 61; b) C. Wäckerlin, K. Tarafder, D. Siewert, J. Girovsky, T. Hählen, C. Iacovita, A. Kleibert, F. Nolting, T. A. Jung, P. M. Oppeneer, et al., Chem. Sci. 2012, 3, 3154-3160. [5] a) A. Scheybal, T. Ramsvik, R. Bertschinger, M. Putero, F. Nolting, T. A. Jung, Chem. Phys. Lett. 2005, 411, 214-220; b) H. Wende, M. Bernien, J. Luo, C. Sorg, N. Ponpandian, J. Kurde, J. Miguel, M. Piantek, X. Xu, P. Eckhold, et al., Nat. Mater. 2007, 6, 516-520; 
c) M. Bernien, J. Miguel, C. Weis, M. E. Ali, J. Kurde, B. Krumme, P. M. Panchmatia, B. Sanyal, M. Piantek, P. Srivastava, et al., Phys. Rev. Lett. 2009, 102, 047202; d) M. E. Ali, B. Sanyal, P. M. Oppeneer, J. Phys. Chem. C 2009, 113, 14381-14383; e) D. Chylarecka, T. K. Kim, K. Tarafder, K. Müller, K. Gödel, I. Czekaj, C. Wäckerlin, M. Cinchetti, M. E. Ali, C. Piamonteze, et al., J. Phys. Chem. C 2011, 115, 1295-1301; f) D. Chylarecka, C. Wäckerlin, T. K. Kim, K. Müller, F. Nolting, A. Kleibert, N. Ballav, T. A. Jung, J. Phys. Chem. Lett. 2010, 1, 1408-1413; g) M. Bernien, X. Xu, J.

Miguel, M. Piantek, P. Eckhold, J. Luo, J. Kurde, W. Kuch, K. Baberschke, H. Wende, et al., Phys. Rev. B 2007, 76, 214406; h) S. Javaid, M. Bowen, S. Boukari, L. Joly, J.-B. Beaufrand, X. Chen, Y. Dappe, F. Scheurer, J.-P.

Kappler, J. Arabski, et al., Phys. Rev. Lett. 2010, 105, 077201; i) N.

Atodiresei, J. Brede, P. Lazicacute, V. Caciuc, G. Hoffmann, R.

Wiesendanger, S. Blügel, Phys. Rev. Lett. 2010, 105, 066601; j) C.

Wäckerlin, J. Nowakowski, S.-X. Liu, M. Jaggi, D. Siewert, J. Girovsky, A.

Shchyrba, T. Hählen, A. Kleibert, P. M. Oppeneer, et al., Adv. Mat. 2013,

doi: 10.1002/adma.201204274; k) J. Miguel, C. F. Hermanns, M. Bernien, A. Krüger, W. Kuch, J. Phys. Chem. Lett. 2011, 2, 1455-1459.

[6] P. Gambardella, S. Stepanow, A. Dmitriev, J. Honolka, F. M. F. de Groot, M. Lingenfelder, S. S. Gupta, D. D. Sarma, P. Bencok, S. Stanescu, et al., Nat Mater 2009, 8, 189-193.

[7] C. Isvoranu, B. Wang, K. Schulte, E. Ataman, J. Knudsen, J. N.

Andersen, M. L. Bocquet, J. Schnadt, J. Phys.: Condens. Matter 2010, 22, 472002.

[8] a) N. Tsukahara, K. Noto, M. Ohara, S. Shiraki, N. Takagi, S. Shin, M. Kawai, Phys. Rev. Lett. 2009, 102, 167203; b) J. Brede, N. Atodiresei, S.

Kuck, P. Lazić, V. Caciuc, Y. Morikawa, G. Hoffmann, S. Blügel, R. Wiesendanger, Phys. Rev. Lett. 2010, 105, 047204.

[9] a) L. G. Teugels, L. G. Avila-Bront, S. J. Sibener, J. Phys. Chem. C 2011 115, 2826-2834; b) W. Auwärter, K. Seufert, F. Klappenberger, J. Reichert,
A. Weber-Bargioni, A. Verdini, D. Cvetko, M. Dell'Angela, L. Floreano, A. Cossaro, et al., Phys. Rev. B 2010, 81, 245403; c) F. Buchner, I. Kellner, W. Hieringer, A. Görling, H.-P. Steinrück, H. Marbach, Phys. Chem. Chem. Phys. 2010, 12, 13082.

[10] L. Bartels, M. Wolf, T. Klamroth, P. Saalfrank, A. Kühnle, G. Meyer, K.-H. Rieder, Chem. Phys. Lett. 1999, 313, 544-552.

[11] a) J. Stöhr, H. C. Siegmann, Magnetism: From Fundamentals to Nanoscale Dynamics, Springer, Berlin, 2006; b) U. Flechsig, F. Nolting, A. Fraile Rodríguez, J. Krempaský, C. Quitmann, T. Schmidt, S. Spielmann, D. Zimoch, R. Garrett, I. Gentle, et al., AIP Conf. Proc. 2010, 1234, 319-322. [12] F. A. Cotton, G. Wilkinson, A. C. Murillo, M. Bochmann, Advanced inorganic chemistry, Wiley, New York, 1999.

[13] a) L. X. Chen, W. J. H. Jäger, G. Jennings, D. J. Gosztola, A.

Munkholm, J. P. Hessler, Science 2001, 292, 262-264; b) H. Duval, V.

Bulach, J. Fischer, R. Weiss, Inorg. Chem. 1999, 38, 5495-5501; c) S. Thies, C. Bornholdt, F. Köhler, F. D. Sönnichsen, C. Näther, F. Tuczek, R. Herges, Chem. Eur. J. 2010, 16, 10074-10083; d) S. Venkataramani, U. Jana, M. Dommaschk, F. D. Sonnichsen, F. Tuczek, R. Herges, Science 2011, 331, 445-448.

[14] P. M. Oppeneer, P. M. Panchmatia, B. Sanyal, O. Eriksson, M. E. Ali, Prog. Surf. Sci. 2009, 84, 18-29.

[15] a) K. Flechtner, A. Kretschmann, H.-P. Steinrück, J. M. Gottfried, J. Am. Chem. Soc. 2007, 129, 12110-12111; b) M. G. Betti, P. Gargiani, R.

Frisenda, R. Biagi, A. Cossaro, A. Verdini, L. Floreano, C. Mariani, J. Phys. Chem. C 2010, 114, 21638-21644; c) W. Hieringer, K. Flechtner, A. Kretschmann, K. Seufert, W. Auwärter, J. V. Barth, A. Görling, H.-P Steinrück, J. M. Gottfried, J. Am. Chem. Soc. 2011, 133, 6206-6222. 
Layout 2:

\section{On-Surface Magnetochemistry}

Christian Wäckerlin, Kartick Tarafder, $\ddagger$ Jan Girovsky, Jan Nowakowski, Tatjana Hählen, Aneliia Shchyrba, Dorota

Siewert, Armin Kleibert, Frithjof Nolting, Peter M. Oppeneer, Thomas A. Jung* and Nirmalya Ballav*

Page - Page

Ammonia Coordination Introducing a Magnetic Moment in On-Surface LowSpin Porphyrin
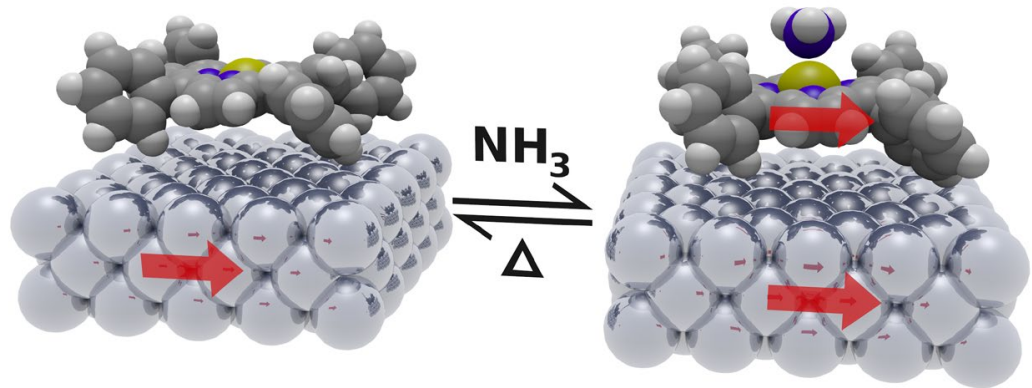

Amazing ammonia! The molecular spin state of $\mathrm{Ni}(\mathrm{II})$ porphyrin, supported on a ferromagnetic Co surface, can be reversibly switched between spin-off $(S=0)$ and spin-on $(\mathrm{S}=1)$ states upon coordination and decoordination of gaseous ligand $\mathrm{NH}_{3}$, respectively. This finding clearly indicates the possible use of the system as a magnetochemical sensor and could also find applications in molecular spintronics. 